\section{Residential Energy-Efficiency Equipment Shown to be a Good Investment for U.S. Navy}

A two-year project between the National Renewable Energy Laboratory (NREL) and the U.S. Navy's Naval Facilities Engineering Command (NAVFAC) to demonstrate energy efficiency technologies at bases in Hawaii and Guam resulted in the identification of several promising options for reducing energy use and costs, including whole-house energy efficiency retrofits.

The retrofit technologies made up one component of a larger project that addressed other efficiency measures, renewable energy generation, and energy systems integration. The task focused on identifying new or underutilized commercial technologies that could help meet the Navy's ambitious energy goals of producing at least $50 \%$ of shore-based energy from alternative sources and ensuring that $50 \%$ of Navy and Marine Corps installations will be net-zero energy.

A collaborative effort by the NREL-NAVFAC integrated project team was a key success factor to the project, resulting in technology demonstrations that met stringent Navy requirements while providing credible performance data to help guide energy-related decisions.

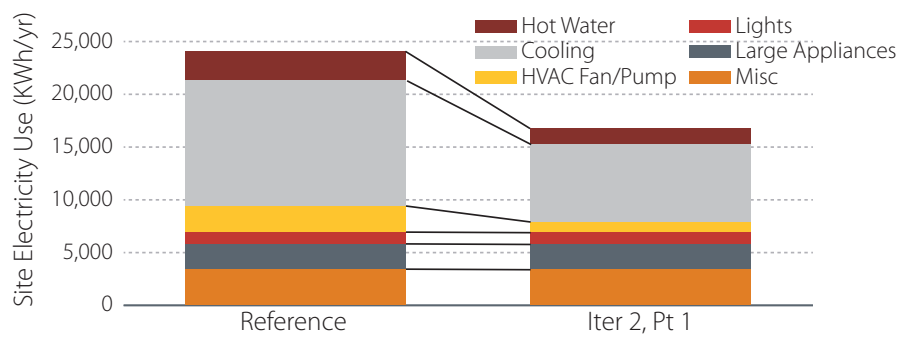

Simulated annual energy consumption by end use for pre- and post-retrofit Navy base home

\section{The Technology Demonstration}

\section{Overview}

The NREL-NAVFAC team demonstrated whole-house energy efficiency retrofits in military housing on Naval Base Guam.

\section{Key Results}

The retrofit technologies showed promising cost and energy savings, with an annual savings of 4,000 kilowatthours (kWh) in air-conditioning use and 1,400 kWh in water heating use per home.

\section{Whole-House Energy Efficiency Retrofits}

Considerable savings were seen by implementing aggressive energy efficiency retrofits in eight demonstration homes. The retrofits consisted of installing heat pump water heaters and high-efficiency air conditioners coupled with programmable thermostats and low-flow shower heads, and saved an average of 4,000 kilowatt-hours (kWh) in air-conditioning use and 1,400 $\mathrm{kWh}$ in water heating use per home per year. With high electricity costs of $50 \mathrm{c} / \mathrm{kWh}$ in Guam, this translates to a projected net savings of $\$ 15,000$ per home over the next 10 years after paying for the initial investment in the first three years.

As a result of the findings, Naval Base Guam is implementing some of the technologies demonstrated, and has made heat pump water heaters and high-efficiency air conditioners the new equipment standard.

To learn more about the demonstration projects, download the NAVFAC Hawaii and Guam Energy Improvement Technology Demonstration Project reports at nrel.gov, visit NREL's Department of Defense website at www.nrel.gov/defense/, or contact Jeffrey Dominick at jeffrey.dominick@nrel.gov. 